\title{
Interactive comment on "Impact of air pollution control measures and regional transport on carbonaceous aerosols in fine particulate matter in urban Beijing, China: Insights gained from long-term measurement” by Dongsheng Ji et al.
}

Anonymous Referee \#2

Received and published: 9 April 2019

General Comments:

This research is to investigate the $\mathrm{OC}$ and $\mathrm{OC}$ hourly concentration variation in Beijing, China from 2013 to 2018. Based on data, authors discussed the relationship between $\mathrm{OC}$ and $\mathrm{EC}$, and with major air pollutants and sources via inter-annual, seasonal, weekly and diurnal variations. Finally NWR and PSCF were employed to evaluate the local and regional anthropogenic sources. In general, the data of this manuscript are informative and this paper fits the scope of ACP. Please modify the manuscript based on the following comment before ACP publication.

Printer-friendly version

Discussion paper 
Comments:

1. Section 3.1, page 9, Table 2 contains a lot of data, and the source of data should be ACPD acknowledged. I could not see the importance of Table 2 in the main text, and suggest that Table 2 can be shifted to supporting information.

2. Page 10, line 237, it should be "Table 3", not Table 2. In Table 3, what are the meaning for TOT and TOT? Please explain both of them by note in the table. (Same with Table 4).

3. Page 10, lines 254-255, what criteria did authors classify PM2.5 different air quality levels as excellent, good, slightly polluted, moderately polluted, heavily polluted and severely polluted? Please specify in the text.

4. Page 10, line 254, in Fig. 2, "White Block" label is referring to PM2.5 in both two figures?

5. Section 3.2, page 11, Fig. 4 can be part of Fig. 3. Does Fig. 4 contain special information? If yes, some more discussion related to Fig. 4 should be added. Otherwise I recommended to remove this figure.

6. Page 11, I found quite a lot of data in Fig. 3 including OC-EC during 2002-2012, $\mathrm{SO} 2, \mathrm{NO} 2$, fire spots, please specify the data sources of all these data.

7. Page 12, lines 302-305, authors claims that biomass burning could contribution a lot to $\mathrm{OC}$ and EC, please be noted that fire spots in 2012 were highest, please add some discussion in this section.

8. Section 3.3, pages 12-14, authors separately discussed monthly and seasonal variations. Actually, I found quite a lot of data explanations are similar for both monthly and seasonal variation. Is it possible for authors to combine both to simplify the discussion?

9. Section 3.4, page 14, lines 365-367, EC concentrations increased starting from 17:00 because of evening rush hours, I am curious why morning rush hour did not 
result in the increase of $\mathrm{EC}$ ?

10. Section 3.5, similar to the above comment No. 6 , please specify the data source of gaseous pollutants.

11. Page 18, 2nd paragraph, authors discussed the relationship between ozone and $\mathrm{OC}$. It is interesting to find that $\mathrm{O} 3$ at $50 \mathrm{ug} / \mathrm{m} 3$ represented the highest $\mathrm{OC}$, and $\mathrm{OC}$ increased with ozone for $\mathrm{O} 3$ concentration above $100 \mathrm{ug} / \mathrm{m} 3$. More discussion of the potential reasons will definitely enhance the quality of manuscript.

12. Section 3.6, page 19, line 493, no Fig. 14 and 15 are in the whole manuscript.

Interactive comment on Atmos. Chem. Phys. Discuss., https://doi.org/10.5194/acp-2019-42, 2019. 